\title{
Potencial alelopático de bioextratos dos resíduos da cana-de-açúcar no controle de bidens pilosa e taraxacum officinale
}

\author{
Ferreira, Nubia Paula ${ }^{1,4}$; Jhansley Ferreira Mata ${ }^{2}$; Allynson Takehiro Fujita ${ }^{2}$; Heytor Lemos \\ Martins ${ }^{1}$; Paula Roberta Fagundes Paula ${ }^{3}$
}

${ }^{1}$ Universidade do Estado de Minas Gerais, Unidade Frutal, Minas Gerais, Brasil; ${ }^{2}$ Departamento de Ciências Exatas e da Terra, Universidade do Estado de Minas Gerais, Minas Gerais, Brasil; ${ }^{3}$ Universidade do Estado de Minas Gerais, Unidade Ituiutaba, Minas Gerais, Brasil; ${ }^{4}$ nubiadepaula17@gmail.com

Ferreira, Nubia Paula; Jhansley Ferreira Mata; Allynson Takehiro Fujita; Heytor Lemos Martins; Paula Roberta Fagundes Paula (2020) Potencial alelopático de bioextratos dos resíduos da cana-de-açúcar no controle de bidens pilosa e taraxacum officinale. Rev. Fac. Agron. Vol 119 (1): 1-11. https://doi.org/10.24215/16699513e032

\begin{abstract}
O trabalho teve como objetivo avaliar o potencial alelopático de resíduos da cana-de-açúcar utilizando bioensaios na germinação de sementes e crescimento de plantas daninhas e plantas bioindicadoras. As doses do bioextrato de palha da cana-de-açúcar estimulou o comprimento da parte aérea das plantas daninhas (dente-de-leão e picão-preto) e inibiu o seu percentual de germinação. As doses de palha da cana-de-açúcar podem inibir ou estimular o desenvolvimento das espécies em estudo. As espécies foram inibidas quando pulverizado o pó da palha da cana-de-açúcar em todas as variáveis analisadas. Com os resultados deste estudo, verifica-se a necessidade da continuação deste trabalho, onde poderá ser isolado e identificado o composto fitoquímico de interesse do pó da palha e do bioextrato da palha de cana-de-açúcar, sendo utilizado como controle natural nas fases de germinação e/ou desenvolvimento de plântula ou planta de espécies daninhas (dente-de-leão e picãopreto).
\end{abstract}

Palavras-chave: alelopatia, cana-de-açúcar, plantas daninhas, bioextratos, palha e inibição

Ferreira, Nubia Paula; Jhansley Ferreira Mata; Allynson Takehiro Fujita; Heytor Lemos Martins; Paula Roberta Fagundes Paula (2020) Allelophatic potential of bio-extracts from sugar cane residues in control of bidens pilosa and taraxacum officinale. Rev. Fac. Agron. Vol 119 (1): 1-11. https://doi.org/10.24215/16699513e032

The objective of this work was to evaluate the allelopathic potential of sugarcane residues using bioassays in seed germination and weed and bioindicator plant growth. The doses of sugarcane straw bioextract stimulated the length of the weeds shoot (dandelion and black prick) and inhibited their germination percentage. Sugarcane straw doses may inhibit or stimulate the development of the species under study. The species were inhibited when powdered sugarcane straw was pulverized in all the variables analyzed. With the results of this study, it is necessary to continue this work, where it can be isolated and identified the phytochemical compound of interest of the straw powder and the sugarcane straw bioextract, being used as natural control in the phases germination and/or development of seedlings or weeds (dandelion and black prick).

Key words: allelophathy, sugar cane, weeds, bio-indicators, bio-extract, straw and inhibition

https://revistas.unlp.edu.ar/revagro

Recibido: 07/01/2019

Aceptado: $13 / 11 / 2019$

Disponible on line: $01 / 07 / 2020$

ISSN 0041-8676 - ISSN (on line) 1669-9513, Facultad de Ciencias Agrarias y Forestales, UNLP, Argentina 


\section{INTRODUÇÃO}

A cultura da cana-de-açúcar (Saccharum spp.) exerce importante papel na economia brasileira, principalmente pela grande produção alcançada nos últimos anos, colocando, assim, o Brasil como o maior produtor mundial de cana-de-açúcar. Os Estados de São Paulo, Goiás e Minas Gerais são os maiores produtores brasileiros, onde Minas Gerais, com o terceiro lugar, participa com $9,3 \%$ do volume estimado de cana-deaçúcar para a produção de açúcar e etanol na safra 2016/17 que representa 64,64 milhões de toneladas (CONAB, 2016). Do volume produzido em Minas Gerais, cerca de $70 \%$ são registradas na região do Triângulo Mineiro (CONAB, 2014).

A colheita mecanizada da cana-de-açúcar está presente nos sistemas de produção no Brasil, onde não ocorre a queima de folhas, bainhas, ponteiro, além de quantidade variável de pedaços de colmo (Trivelin et al., 1996).

A palha depositada sobre o solo interfere diretamente na comunidade infestante através da liberação de compostos alelopáticos, da mudança na quantidade e no balanço de comprimentos de onda de luz que atingem o solo, altera o regime térmico, constitui uma barreira física a emergência e altera a intensidade do controle biológico de sementes e plântulas (Rossi, 2007).

A cobertura morta pode atuar como um valioso elemento no controle de plantas daninhas, uma vez que o terreno coberto por resíduos vegetais apresenta infestação inferior àquele que se desenvolve com o solo descoberto (Almeida, 1992; Severino e Christoffoleti, 2001).

Assim, as plantas daninhas também podem interferir diretamente depreciando a qualidade do produto colhido. Podendo, afetar a pureza da cana. Segundo Soares et al. (2011), a presença de palhada na superfície do solo pode modificar as condições para a germinação de sementes e emergência das plântulas, devido ao efeito físico da cobertura e liberação de substâncias alelopáticas.

A alelopatia ocorre com a liberação de metabólitos secundários, denominados aleloquímicos, no ambiente em função da decomposição dos resíduos vegetais, podendo interferir na germinação, pela inativação dos mecanismos de dormência, e também no crescimento inicial de plantas daninhas ocorrentes (Gomes Junior e Christoffoleti, 2008; Monquero et al., 2009).

Existem vários estudos com efeitos inibitórios no desenvolvimento e crescimento de plantas. Assim, como o trabalho desenvolvido por Santos (2002) onde verificou que a matéria seca do milho quando incorporada ao solo, afetou negativamente o incremento da área foliar, altura e diâmetro do caule das plantas de café. Oliveira, Constantin e Inoue. (2011) verificaram efeito inibitório no desenvolvimento das plântulas de picão-preto.

Em projetos realizados por Ribeiro e Lima (2012) foi verificada uma redução no comprimento das raízes e da parte aérea em mudas da espécie Euphorbia heterophylla $L$ (leteiro), provocado pelo contanto com o vapor do óleo essencial da casca da laranja 28 (Citrus sinensis). A má formação das raízes secundárias e lesões diversas também foram verificadas pelos mesmos autores na espécie Ipomoea grandifolia comumente conhecida por corda-de-viola.

Algumas substâncias fitotóxicas são suspeitas de causar inibição na germinação de sementes e no crescimento de plantas, identificados em tecidos da planta e no solo. A maioria destes são compostos fenólicos, que possuem efeito alelopático, processo que inclui o efeito prejudicial direto ou indireto da planta na germinação, crescimento e desenvolvimento de outra planta (Zaprometov, 1992).

Em estudo realizado por Chou (1992) foi observado que a presença do aleloquímicos ácido fenólicos na palha inibiu o crescimento de raízes da Brachiaria brizantha.

Corroborando com este estudo, Seifert e Voll (2000) afirmam que os efeitos químicos provocados pela cobertura morta nas culturas podem causar a deformação ou atrofiamento das raízes das plantas.

Também, sobre efeitos alelopáticos em plantas, tem-se em plantas a dopamina e os resultados demonstraram características de um aleloquímico típico (Wichers et al., 1993; Guidotti et al., 2013). Segundo Guidotti et al. (2013), a exposição de plântulas de soja a dopamina, reduziu o comprimento das raízes e a massa, tanto da raiz fresca quanto da raiz seca.

Bianchi et al. (2011) observaram que quando o Raphanus spp. até os 60 dias após a emergência, o desenvolvimento da cultura foi afetado, acarretando em alterações morfológicas (estatura, número e comprimento de ramos). Em relação às plantas daninhas, alguns autores reportam que espécies predominantes na cultura de cana-de-açúcar apresentam comportamento diferenciado em função da quantidade de palha depositada no solo (Medina Melendez, 1990; Velini \& Negrisoli, 2000). Gomes et al. (2014) relatam o efeito físico e químico da cobertura morta na germinação de sementes e na taxa de sobrevivência das plântulas de algumas espécies.

A importância de cada espécie de planta daninha pode variar com a região e, às vezes, dentro de uma mesma propriedade. Algumas, no entanto, são comuns e se destacam pelas dificuldades de controle e pelos problemas que causam ao agricultor (Gazziero e Souza, 1993).

Assim, o presente trabalho teve como objetivo avaliar o potencial alelopático de resíduos da cana-de-açúcar utilizando bioensaios na germinação de sementes e crescimento de plantas daninhas e plantas bioindicadoras.

\section{MATERIAL E MÉTODO}

O estudo foi conduzido em laboratório e casa de vegetação da estação experimental da Universidade do Estado de Minas Gerais (UEMG), Unidade Frutal - MG, em altitude de $430 \mathrm{~m}$. O solo utilizado nos vasos foi classificado como Latossolo Vermelho Distrófico típico (EMBRAPA, 2018).

Os resíduos foram coletados após a colheita da canade-açúcar crescidas na Fazenda Cerradão, no Município de Frutal, Estado de Minas Gerais, no ano de 2016. Onde foram secos a $40^{\circ} \mathrm{C}$, até atingir massa seca constante, logo após foram moídos em um moinho industrial "tipo Willey" até a obtenção de um pó com peneira de malha 20 mesh. 
Os extratos aquosos dos resíduos foram preparados em uma proporção de $100 \mathrm{~g}$ do resíduo secos pulverizados em $1000 \mathrm{~mL}$ de água destilada, produzindo $10 \%\left(\mathrm{v} \mathrm{v}^{-1}\right)$ do extrato, em seguida passou pelo processo de filtração. O extrato concentrado foi colocado em uma proveta e diluído a 2,5; 5,0; 7,5 e $10 \%$ com água destilada e o padrão $(0 \%)$ somente com água destilada.

Do extrato concentrado foi monitorado: $\mathrm{pH}$, condutividade elétrica e temperatura: através de uma sonda multiparâmetros Hanna (HI 9828). Para adequação quanto ao equilíbrio do sistema.

As sementes de Bidens pilosa e Taraxacum officinale passaram por limpeza e esterilização com hipoclorito de sódio a $1 \%$ por três minutos. Logo após foram lavadas com água destilada.

Para o teste de germinação, o delineamento utilizado foi o inteiramente casualizado, com quatro repetições, em que foram utilizadas espécies de plantas daninhas (Bidens pilosa e Taraxacum officinale) e plantas bioindicadoras (Lactuca sativa e Solanum lycopersicum), e 5 concentrações do extrato do resíduo da cana-de-açúcar, 0; 2,5; 5,0; 7,5 e 10\%.

Em cada placa de Petri com dois discos de papel-filtro, foram colocadas 50 sementes de cada planta daninha e planta teste indicadoras, umedecidas com $7 \mathrm{~mL}$ de água destilada (tratamento controle) ou dos extratos vegetais. O experimento foi mantido em câmaras de germinação do tipo ideal para Demanda Bioquímica de Oxigênio(DBO) com temperatura e luminosidade controladas $\left(25 \pm 2^{\circ} \mathrm{C}\right)$, sob fotoperíodo de 12 horas. Foram consideradas germinadas as sementes que apresentarem $2 \mathrm{~mm}$ de protrusão radicular (BRASIL, 2009). Os parâmetros avaliados foram: percentagem de germinação, comprimento de radícula e parte aérea, e índice de velocidade de germinação (IVG).

Para o acompanhamento do desenvolvimento das plântulas utilizou a mensuração do comprimento em milímetros $(\mathrm{mm})$ da radícula e da parte aérea, no final dos 10 dias de experimento.

O índice de velocidade de germinação foi calculado pelo somatório do número de sementes germinadas a cada dia, dividido pelo número de dias decorridos entre a semeadura e a germinação, de acordo com a fórmula de Maguire (1962). Foram calculados por:

$$
\begin{gathered}
(\mathrm{Eq} .1) \quad \text { IVG } \\
\left(\mathrm{G}_{n} / \mathrm{N}_{n}\right)^{2} \text {, em que: }
\end{gathered}
$$

IVG = índice de velocidade de germinação; $\mathrm{Gn}=$ número de plântulas computadas na primeira, segunda, terceira e última contagem; $\mathrm{Nn}=$ número de dias da semeadura à primeira, segunda, terceira e útima contagem.

No experimento em casa de vegetação, foi utilizado vasos de $5 \mathrm{~L}$ com solo calcariado e adubado, conforme análise de solo e ficaram em repouso por 40 dias. Após os 40 dias de repouso, foram semeadas 10 sementes de cada planta daninha e 5 sementes de plantas teste indicadoras por vaso, sendo que, após 15 dias da semeadura foram conduzidas apenas uma planta por vaso.

Utilizou-se delineamento experimental inteiramente casualizado, com 4 repetições, em que foram utilizadas espécies de plantas daninhas e plantas teste indicadoras, com 7 doses do pó da matéria seca do resíduo da cana-de-açúcar, $0 ; 0,5 ; 1 ; 1,5 ; 2 ; 2,5$ e $3 \%$ ( $p$ $\left.\mathrm{p}^{-1}\right)$, que foram adicionadas ao vaso em superfície, incorporados e pulverizados.

Aos 40 dias de desenvolvimento após a semeadura, os vasos foram desinstalados e avaliados os parâmetros: altura das plantas $(\mathrm{cm})$ : medição a partir do solo até a curvatura da última folha; diâmetro do caule $(\mathrm{cm})$ : medição a $2 \mathrm{~cm}$ do solo com um paquímetro digital; volume de raiz $\left(\mathrm{cm}^{3}\right)$ : a raiz foi colocada em uma proveta graduada com $200 \mathrm{~mL}$ de água, onde o volume se deu pela diferença das leituras; comprimento da raiz $(\mathrm{cm})$ : medição com uma régua graduada $(\mathrm{cm})$; massa verde da parte aérea $(\mathrm{g})$ e massa verde da raiz $(\mathrm{g})$ : após retira do vaso, a parte aérea e raiz foram separadas, e mensurada suas massas; massa seca da parte aérea ( $\mathrm{g}$ ) e massa seca da raiz (g): foram colocadas em estufa de circulação de ar forçada, a $60^{\circ} \mathrm{C}$, até atingir massa seca constante e mensurada suas massas.

Os resultados obtidos dos parâmetros avaliados foram submetidos à análise de variância, os dados qualitativos foram avaliados através do teste de Skottknott ao nível de $5 \%$ de probabilidade, utilizando o programa estatístico SISVAR (Ferreira, 2011. Para os dados quantitativos, foram ajustados os modelos conforme a sua significância e o coeficiente de determinação $\left(R^{2}\right)$, com base nas recomendações de Venegas e Alvarez (2003), e a análise dos resultados foram submetidas à análise regressão utilizando o programa estatístico Microcal Origin 6.1 (2000).

\section{RESULTADOS E DISCUSSÃO}

Na Tabela 1, observa-se a monitoração do extrato aquoso da palha de cana-de-açúcar, com pH 3,37; condutividade elétrica $6056 \mu S^{2} / \mathrm{cm}$ e temperatura $23,69^{\circ} \mathrm{C}$.

Tabela 1. Valores de $\mathrm{pH}$, condutividade elétrica e temperatura do bioextrato da palha da cana-de-açúcar.

\begin{tabular}{ccc}
\hline pH & Condutividade elétrica & Temperatura \\
\hline 3,37 & $6056 \mu \mathrm{S}^{2} / \mathrm{cm}$ & $24,69^{\circ} \mathrm{C}$ \\
\hline
\end{tabular}

$\mathrm{O}$ pH ácido pode ajudar na germinação de sementes, uma vez que, agride o tegumento das sementes, o tegumento possui certa dureza e essa dureza impede a semente de responder o ambiente externo, podendo as sementes apresentar maior condutividade elétrica.

Analisando a germinação das sementes (Figura 1A), verifica-se diferença estatística ao nível de 1 e $5 \%$ para as espécies de picão-preto e dente-de-leão.

Para as sementes da espécie dente-de-leão no final do período de 10 dias, observa-se que todas as doses afetaram as sementes, caracterizando redução da germinação nas seguintes proporções: 9,52\%; 
$20,24 \% ;, 34,29 \%$ e $50,76 \%$ para as doses de 2,$5 ; 5,0$; 7,5 e $10 \%$, em relação à testemunha.

Já na germinação de sementes de picão-preto, verificase redução da germinação nas dosagens de 2,5; 5,0; 7,5 e 10\% com percentuais de 3, 8, 13 e 18, em relação à testemunha.

No entanto, para as sementes de tomate e alface não houve diferença significativa entre as doses de bioextrato.

Segundo Ferreira \& Borghetti (2004), a germinabilidade talvez seja a mais simples forma de representar a porcentagem de sementes germinadas em relação ao número de sementes dispostas a germinar sob determinadas condições experimentais.

Medina-Melendez (1990) corrobora com este estudo afirmando que o palhiço da cana-de-açúcar reduziu a um nível considerável a germinação das sementes de Bidens pilosa. Além do mais, o uso destas coberturas vem de forma complementar o método químico de controle de plantas daninhas, pois resíduo da cultura anterior pode vir a reduzir bem como atrasar a emergência destas plantas (Rizzardi \& Silva 2006).

No comprimento radicular das plântulas (Figura IB) não apresenta diferença significativa entre as doses de bioextrato. O comprimento radicular das espécies de tomate e dente-de-leão, em relação à testemunha, foi inibido quando aplicado doses bioextrato. Já para o comprimento radicular de alface e picão-preto, as doses aplicadas estimularam o seu comprimento, em relação à testemunha.

Analisando o comprimento da parte aérea das plântulas (Figura IC), as espécies de tomate e alface não diferiram estatisticamente. No entanto, as espécies de plantas daninhas (picão-preto e dente-de-leão) diferiram estatisticamente, ao nível de $5 \%$ de probabilidade.

Para as plântulas de dente-de-leão e picão-preto, verificou estímulo em todas as doses do bioextrato $(2,5 \%, 5,0 \%, 7,5 \%$ e $10 \%)$ no desenvolvimento da parte aérea, em relação à testemunha, com a proporção de $14,88 \%$; 33,33\%; $1,68 \%$ e $59,52 \%$, respectivamente, para a espécie dente-de-leão e 5,48\%, 11,47\%, 19,06\% e $25,73 \%$.

Conforme efeito do bioextrato no comprimento da parte aérea das plântulas (Figura IC) verifica-se efeito contrário à germinação das sementes, onde estimulou o crescimento da parte aérea.

O índice de velocidade de germinação é uma medida quantitativa da germinação que relaciona o número de sementes germinadas com o número de dias de semeadura: quanto maior o IVG, maior será a velocidade de germinação, o que permite quantificar o vigor dos lotes de sementes, ou seja, verificar se germinarão mais sementes em poucos dias, Ferreira $\mathrm{E}$ Borghetti (2004).

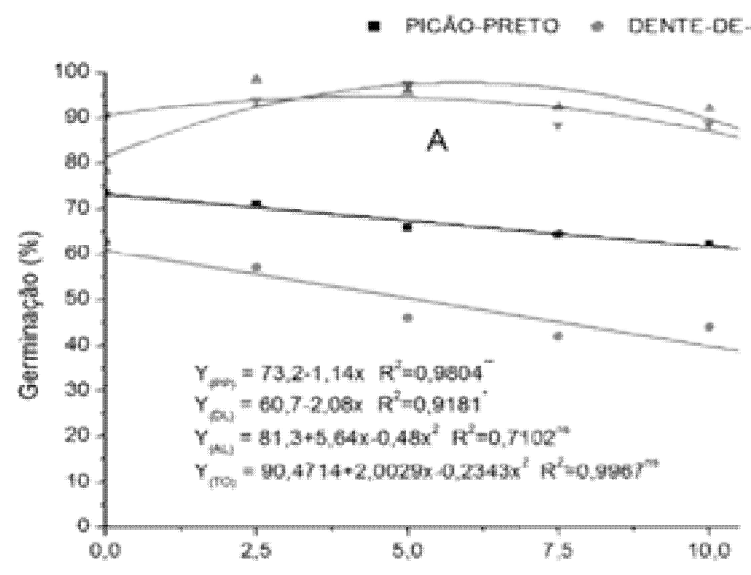

AO - ALFACE $\%$ TOMATE
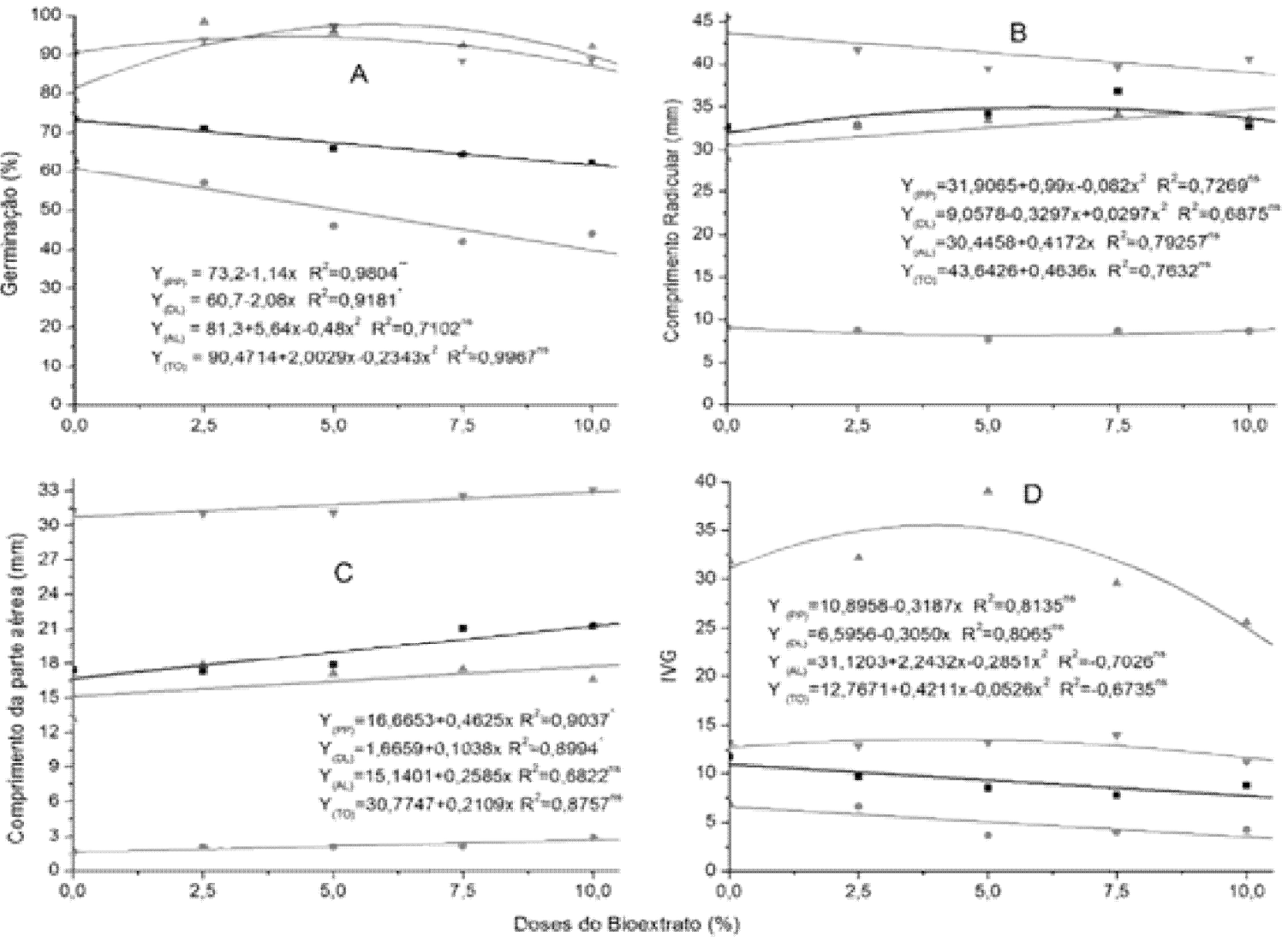

Figura 1. Efeito do percentual das doses do bioextrato da palha de cana-de-açúcar em: A: Percentagem da germinação de sementes; B: Comprimento radicular das plântulas $(\mathrm{mm})$; C: Comprimento da parte aérea das plântulas (mm); D: IVG - Índice de Velocidade de Germinação. Nas espécies de Picão-Preto, Dente-de-Leão, Alface e Tomate. 
Analisando o IVG das sementes (Figura ID) não verifica-se diferença significativa entre as doses de bioextrato. O IVG das sementes de picão-preto e dentede-leão diminuiu com o aumento das doses de bioextrato, no decorrer dos 10 dias.

Também foi analisado IVG das sementes de alface que verificou incremento nas doses de 2,5\%,5,0\% e 7,5\% e inibição na dose de $10 \%$, ao longo dos dez dias de avaliação, em relação à testemunha $(0 \%)$.

Para as sementes de tomate o IVG, em relação à testemunha, foi estimulado nas doses de 2,5 e $5,0 \%$ e já nas doses de 7,5 e 10\% refrearam a velocidade da germinação.

Analisando a altura entre as doses de bioextrato para cada tipo de aplicação (TDA) de palha da cana-deaçúcar e espécie, Tabela 2, as doses não diferiram estatisticamente para as espécies de alface e tomate. No entanto, para as espécies de dente-de-leão e picãopreto verifica-se diferença estatística, com maiores valores nas doses de 0 e $0,5 \%$, e nas demais doses observa-se inibição na altura da planta. Quando a palha foi incorpora, observa-se que na espécie de alface as doses não deferiram estatisticamente. Já para espécie de tomate houve diferença estatística observando maiores valores nas doses de 0 e 1,5\% e nas espécies de dente-de-leão e picão-preto observa-se maiores valores nas dosagens de 0; 2,5 e 3\% e nas demais verifica-se a inibição na aluta da planta.

Comparando os tipos de aplicação para as doses de bioextrato entre a mesma espécie (Tabela 2), verificase que não difere estatisticamente entre a aplicação pulverizada e incorporada para as espécies de alface e tomate. No entanto, para as espécies de dente-de-leão e picão-preto, observa-se diferença significativa, sendo que, quando a palha foi pulverizada observam-se maiores valores nas doses $0,5 \%$ para as espécies de dente-de-leão e picão-preto.

Considerando o comprimento da raiz das espécies submetidas a diferentes tipos de aplicação de palha da cana-de-açúcar e doses, conforme Tabela 3, foi observado que entre as doses não diferiram estatisticamente quando pulverizado a palha para as espécies de alface e dente-de-leão. No entanto, para a espécie de tomate observa-se diferença estatística e maiores valores nas doses de 0,$5 ; 1$ e 1,5\% quando pulverizado e na espécie de picão-preto maiores valores nas doses de $0 ; 0,5 ; 1 \%$, e nas demais doses observa-se inibição na altura da planta comparada com a testemunha. Em estudo utilizando extrato aquoso de folhas de Emilia sonchifolia (flor pincel).

Já na aplicação incorporada da palha, observa-se que nas espécies de alface, tomate e dente-de-leão as doses não deferiram estatisticamente. No entanto, para a espécie de picão-preto houve diferença estatística observando maiores valores na testemunha $(0 \%)$, verificado assim, inibição no comprimento da raiz quando a palha da cana-de-açúcar foi incorporada.

Comparando os tipos de aplicação entre as dosagens de bioextrato na mesma espécie, verifica-se que não difere estatisticamente entre a aplicação pulverizada e incorporada para a espécie de alface e tomate. No entanto, para a espécie de dente-de-leão e picão-preto, observa-se diferença significativa, quando a palha foi pulverizada considerando maiores valores na dose 0,5\% para a espécie de dente-de-leão e para picãopreto nas doses de 0,5 e $1 \%$.

Analisando o diâmetro do caule das espécies submetidas aos diferentes tipos de aplicação de palha da cana-de-açúcar (Tabela 4), foi observado entre as doses não diferiram estatisticamente quando a palha foi pulverizada e incorporada para todas as espécies.

Tabela 2. Altura das espécies submetidas a diferentes aplicações e doses do bioextrato da palha de cana-de-açúcar. TDA: Tipo de aplicação.Médias seguidas pela mesma letra, minúscula na coluna e maiúscula na linha entre cada espécies, não diferem estatisticamente, ao nível de $5 \%$ de probabilidade, pelo teste de Skott-knott. ${ }^{*} e^{* *}$ significativo a 5 e $1 \%$ de probabilidade, respectivamente. ns: não significativo.

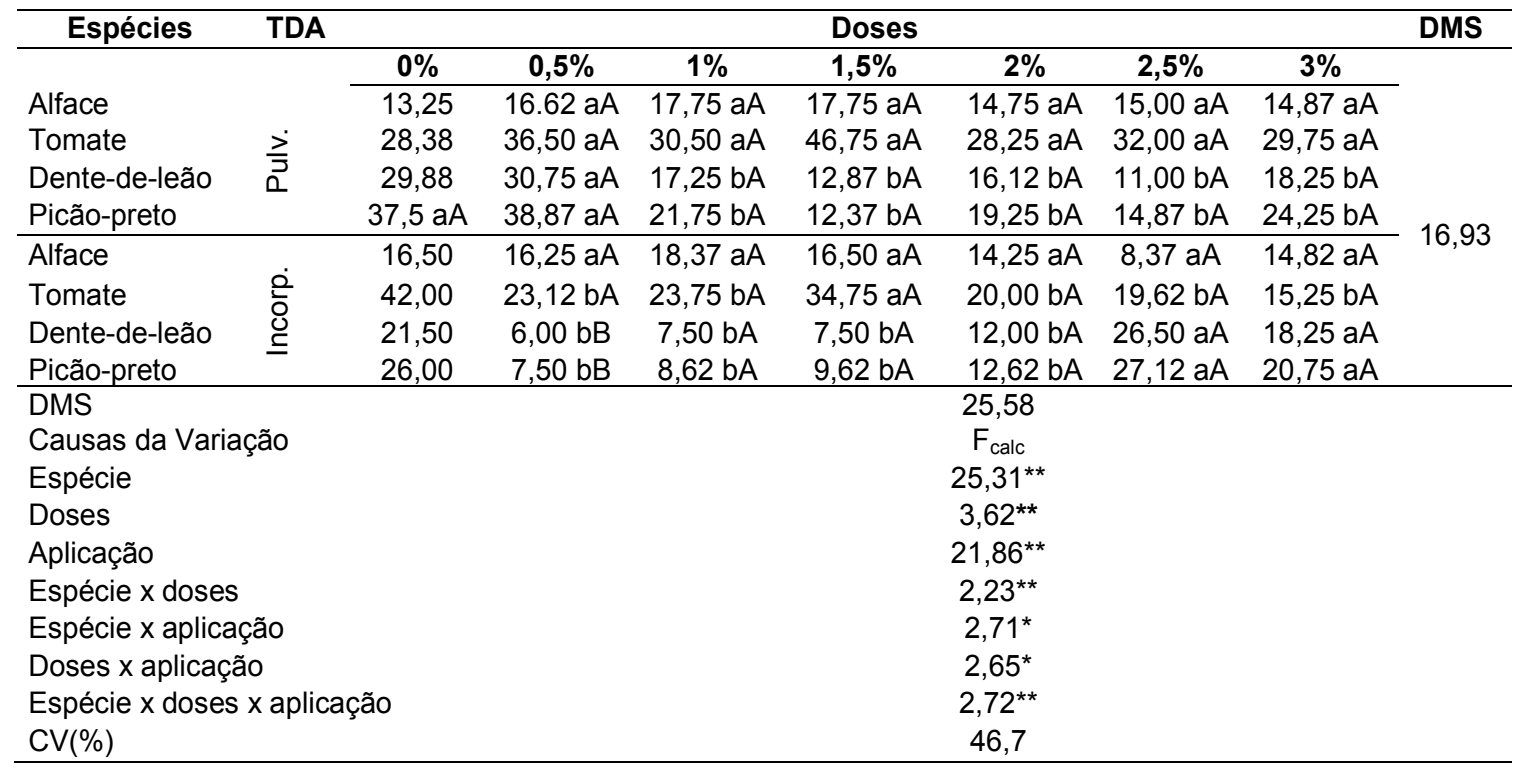


Tabela 3. Comprimento das raízes submetidas a diferentes aplicações e doses do bioextrato da palha de cana-deaçúcar. TDA: Tipo de aplicação. Médias seguidas pela mesma letra, minúscula na coluna e maiúscula na linha entre cada espécies, não diferem estatisticamente, ao nível de $5 \%$ de probabilidade, pelo teste de Skott-knott. * e ${ }^{* *}$ significativo a 5 e $1 \%$ de probabilidade, respectivamente. ns: não significativo.

\begin{tabular}{|c|c|c|c|c|c|c|c|c|c|}
\hline \multirow[t]{2}{*}{ Espécies } & \multirow[t]{2}{*}{ TDA } & \multicolumn{7}{|c|}{ Doses } & \multirow[t]{2}{*}{ DMS } \\
\hline & & $0 \%$ & $0,5 \%$ & $1 \%$ & $1,5 \%$ & $2 \%$ & $2,5 \%$ & $3 \%$ & \\
\hline Alface & \multirow{4}{*}{ 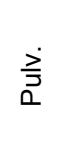 } & $10,25 a A$ & 10,75 aA & $11,25 \mathrm{aA}$ & $13,62 \mathrm{aA}$ & $12,57 \mathrm{aA}$ & 13,00 aA & $10,25 \mathrm{aA}$ & \multirow{8}{*}{12,46} \\
\hline Tomate & & $18,75 \mathrm{bA}$ & $23,62 \mathrm{aA}$ & $25,12 \mathrm{aA}$ & $31,37 \mathrm{aA}$ & $12,62 \mathrm{bA}$ & $17,12 \mathrm{bA}$ & $14,50 \mathrm{bA}$ & \\
\hline Dente-de-leão & & $21,57 \mathrm{aA}$ & $27,42 \mathrm{aA}$ & $22,50 \mathrm{aA}$ & 20,75 aA & $20,12 \mathrm{aA}$ & $11,50 \mathrm{aA}$ & $20,12 \mathrm{aA}$ & \\
\hline Picão-preto & & 26,57 aA & 35,75 aA & $23,50 \mathrm{aA}$ & $17,75 \mathrm{bA}$ & $17,62 \mathrm{bA}$ & $14,50 \mathrm{bA}$ & $13,87 \mathrm{bA}$ & \\
\hline Alface & \multirow{4}{*}{$\begin{array}{l}\dot{0} \\
\text { 음 } \\
\text { 은 }\end{array}$} & $11,37 \mathrm{aA}$ & $14,25 \mathrm{aA}$ & $18,25 a \mathrm{~A}$ & $14,12 \mathrm{aA}$ & 12,00 aA & 6,62 aA & 8,37 aA & \\
\hline Tomate & & 23,12 aA & $13,87 \mathrm{aA}$ & 18,75 aA & $25,87 \mathrm{aA}$ & $15,37 \mathrm{aA}$ & $14,50 \mathrm{aA}$ & $13,87 \mathrm{aA}$ & \\
\hline Dente-de-leão & & 23,75 aA & $8,87 \mathrm{aB}$ & $11,50 \mathrm{aA}$ & $11,25 \mathrm{aA}$ & $12,50 \mathrm{aA}$ & 15,75 aA & $18,45 \mathrm{aA}$ & \\
\hline Picão-preto & & $32,87 \mathrm{aA}$ & $7,00 \mathrm{bB}$ & $9,75 \mathrm{bB}$ & $9,00 \mathrm{bA}$ & $12,25 \mathrm{bA}$ & $18,37 \mathrm{bA}$ & $18,75 \mathrm{bA}$ & \\
\hline DMS & & & & & & 16,83 & & & \\
\hline Causas da Variação & & & & & & $\mathrm{F}_{\text {calc }}$ & & & \\
\hline Espécie & & & & & & $12,32^{\star *}$ & & & \\
\hline Doses & & & & & & $2,98^{* *}$ & & & \\
\hline Aplicação & & & & & & $19,88^{* *}$ & & & \\
\hline Espécie $\mathrm{x}$ doses & & & & & & $2,79^{\star *}$ & & & \\
\hline Espécie $x$ aplicação & & & & & & $3,78^{*}$ & & & \\
\hline Doses $x$ aplicação & & & & & & $3,81^{* *}$ & & & \\
\hline Espécie $\mathrm{x}$ doses $\mathrm{x}$ a & cação & & & & & $2,4^{* *}$ & & & \\
\hline $\mathrm{CV}(\%)$ & & & & & & 43,02 & & & \\
\hline
\end{tabular}

Tabela 4. Diâmetro do caule das espécies a diferentes tipos de aplicações e doses do bioextrato da palha de cana-deaçúcar. TDA - Tipo de aplicação. Médias seguidas pela mesma letra, minúscula na coluna e maiúscula na linha entre cada espécies, não diferem estatisticamente, ao nível de $5 \%$ de probabilidade, pelo teste de Skott-knott. * e ** significativo a 5 e $1 \%$ de probabilidade, respectivamente. ns: não significativo.

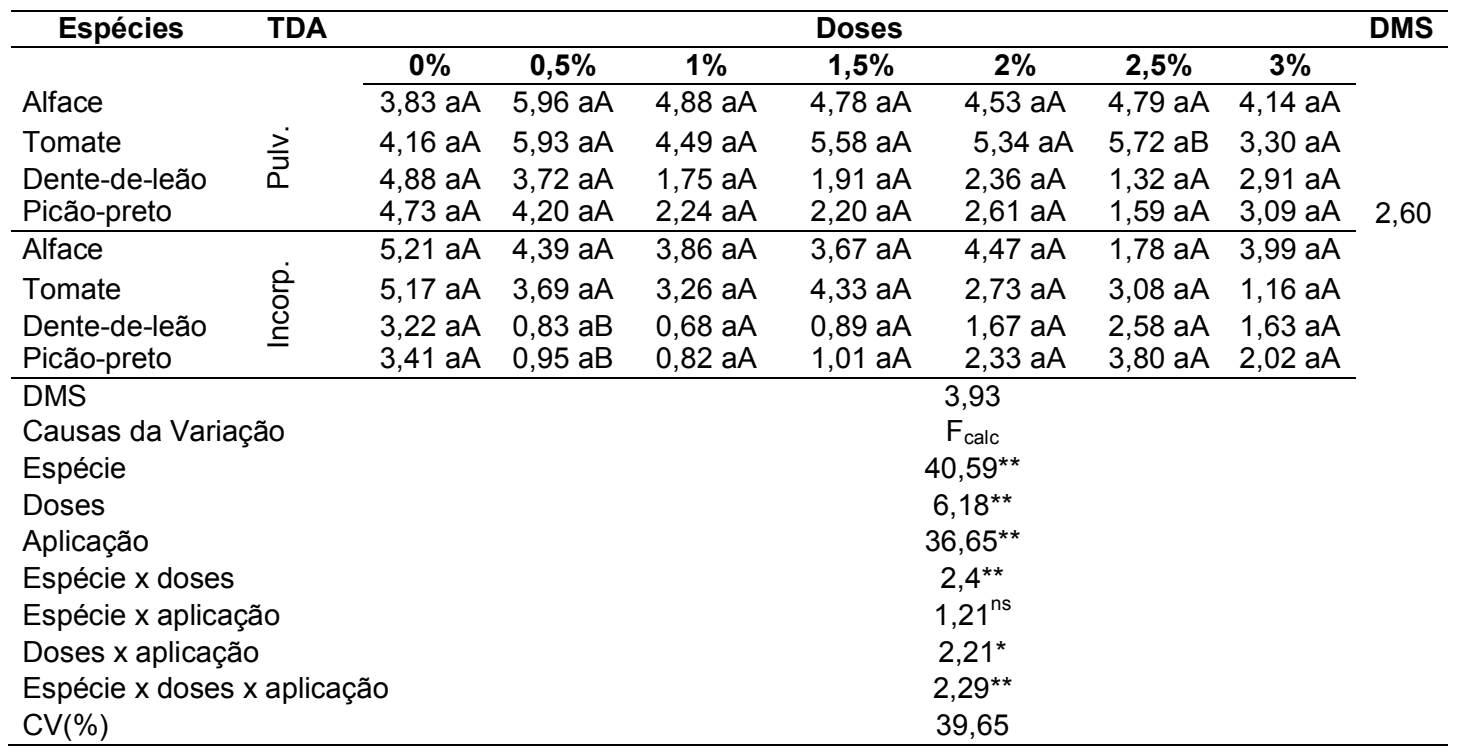

Comparando os tipos de aplicação entre as dosagens de bioextrato em cada espécie, verifica-se que não difere estatisticamente entre a aplicação pulverizada e incorporada para a espécie de alface e tomate. No entanto, para as espécies de dente-de-leão e picãopreto, observa-se diferença significativa, sendo que, quando a palha foi pulverizada observam-se maiores valores na dose $0,5 \%$.

Comparando a massa seca da parte aérea das espécies submetidas a diferentes tipos de aplicação de palha da cana-de-açúcar (Tabela V), foi observado que entre as doses não diferiram estatisticamente quando a palha foi pulverizada nas espécies de alface, tomate e dente-de-leão. 
Entretanto, para a espécie de picão-preto verifica-se diferença estatística, com maiores valores nas doses de 0 e $0,5 \%$, e nas demais doses observa-se redução massa seca da parte aérea da planta.

Quando a palha foi incorpora (Tabela 5), observa-se que na espécie de alface e dente-de-leão as doses não deferiram estatisticamente. Já para espécie de tomate houve diferença estatística com maior valor na dose de $0 \%$ e na espécie de picão-preto observa-se maiores valores nas dosagens de 0 e $3 \%$ e nas demais nota-se a redução na massa seca da parte aérea da planta.

Comparando os tipos de aplicação entre as dosagens de bioextrato na mesma espécie, verifica-se que não difere estatisticamente entre a aplicação pulverizada e incorporadada para a espécie de alface. No entanto, para as espécies de tomate, dente-de-leão e picãopreto, observa-se diferença significativa, sendo que, quando a palha foi pulverizada observam-se maiores valores nas doses $0,5 \%$ e para a espécie de tomate em $2,5 \%$.

Para a massa seca da raiz das espécies submetidas a diferentes tipos de aplicação de palha da cana-deaçúcar, Tabela 6 , observa-se que as doses não diferiram estatisticamente quando a palha foi pulverizada para a espécie de tomate. No entanto, verifica-se diferença estatística, com maiores valores nas doses de 0,$5 ; 1 ; 1,5 ; 2 ; 2,5$ e $3 \%$ para alface, 0 e $0,5 \%$ para dente-de-leão e picão-preto, as demais doses reduziu a massa seca da raiz das plantas.

Verificando quando a palha foi incorporada, nota-se que na espécie de alface que as doses não deferiram estatisticamente. Já para espécie de tomate houve diferença com maior valor na dose $0 \%$ e nas espécies de dente-de-leão e picão-preto observa-se maiores valores na dosagem de 2,5 e $3 \%$, e $3 \%$, respectivamente, e nas demais doses verifica-se menores valores de massa seca radicular.

Analisando os tipos de aplicação nas doses de bioextrato entre a mesma espécie (Tabela VI), verificase que todas as espécies diferem estatisticamente entre a aplicação pulverizada e incorporada. Para a espécie de alface nota-se maioresvalores na testemunha $(0 \%)$, no tomate na dose de $1 \%$, dente-deleão e picão-preto maiores valores nas doses de 0; 0,5 e $3 \%$, sendo que, os maiores valores observados foram quando utilizou a aplicação pulverizada para todas as espécies.

Comparando os valores da massa verde da parte aérea das espécies submetidas a diferentes tipos de aplicação de palha da cana-de-açúcar, Tabela 7, observa-se que as doses não diferiram estatisticamente quando a palha foi pulverizada e incorporada para todas as espécies.

Comparando os tipos de aplicação entre as dosagens de bioextrato na mesma espécie (Tabela VII), não difere estatisticamente entre a aplicação pulverizada e incorporada, para as espécies de tomate, dente-de-leão e picão-preto. No entanto, para a espécie de alface maiores valores foram notados na testemunha, quando pulverizada. Nota-se que a palha quando incorporada inibiu a massa verde da parte aérea da alface.

Analisando a massa verde da raiz das espécies submetidas a diferentes tipos de aplicação de palha da cana-de-açúcar, conforme Tabela VIII, foi observado que as doses não diferiram estatisticamente quando a palha foi pulverizada em todas as espécies.

Para a palha incorpora, observa-se que nas espécies de alface, tomate e dente-de-leão as doses não deferiram estatisticamente. No entanto, para a espécie de picão-preto maiores valores foram nas dosagens de $0 ; 2,5$ e $3 \%$, nas demais doses observa-se redução da massa verde da raiz da planta.

Tabela 5. Massa seca da parte aérea a diferentes tipos de aplicações e doses do bioextrato da palha de cana-deaçúcar. TDA - Tipo de aplicação. Médias seguidas pela mesma letra, minúscula na coluna e maiúscula na linha entre cada espécies, não diferem estatisticamente, ao nível de $5 \%$ de probabilidade, pelo teste de Skott-knott. * e ${ }^{* *}$ significativo a 5 e $1 \%$ de probabilidade, respectivamente. ns: não significativo.

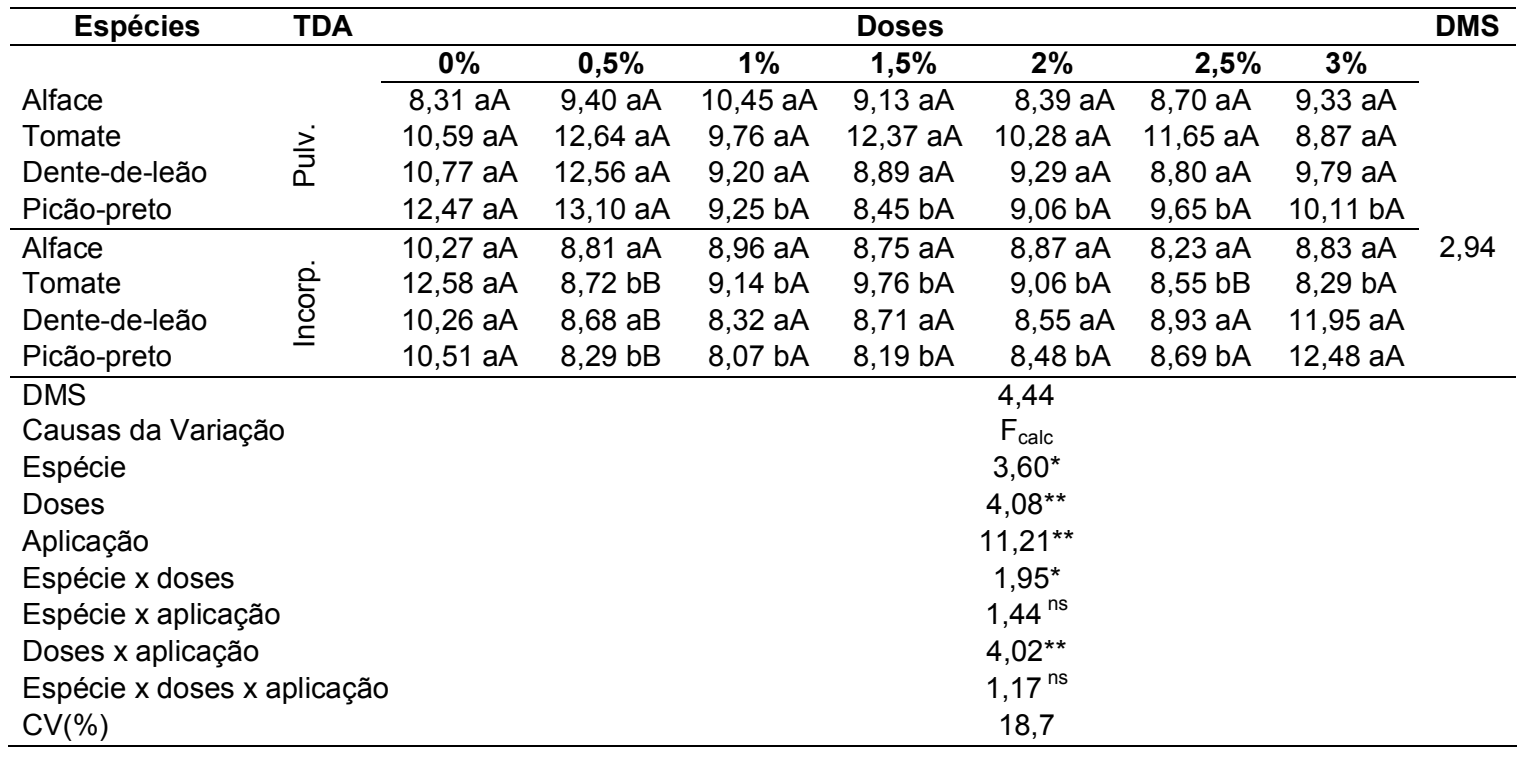


Tabela 6. Massa seca da raiz a diferentes tipos de aplicações e doses do bioextrato da palha de cana-de-açúcar. TDA: Tipo de aplicação. Médias seguidas pela mesma letra, minúscula na coluna e maiúscula na linha entre cada espécies, não diferem estatisticamente, ao nível de $5 \%$ de probabilidade, pelo teste de Skott-knott. * e ** significativo a 5 e $1 \%$ de probabilidade, respectivamente. ns: não significativo.

\begin{tabular}{|c|c|c|c|c|c|c|c|c|c|}
\hline \multirow[t]{2}{*}{ Espécies } & \multirow[t]{2}{*}{ TDA } & \multicolumn{7}{|c|}{ Doses } & \multirow[t]{2}{*}{ DMS } \\
\hline & & $0 \%$ & $0,5 \%$ & $1 \%$ & $1,5 \%$ & $2 \%$ & $2,5 \%$ & $3 \%$ & \\
\hline Alface & \multirow{4}{*}{ 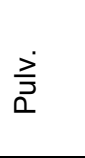 } & $7,15 \mathrm{bA}$ & $8,37 \mathrm{aA}$ & $8,48 \mathrm{aA}$ & $8,37 \mathrm{aA}$ & 8,36 aA & $8,31 \mathrm{aA}$ & 8,24 aA & \multirow{8}{*}{0,83} \\
\hline Tomate & & 8,78 aA & 8,55 aA & $9,30 \mathrm{aA}$ & $8,54 \mathrm{aA}$ & 8,57 aA & $8,55 \mathrm{aA}$ & 8,12 aA & \\
\hline Dente-de-leão & & 9,08 aA & 9,45 aA & $8,56 \mathrm{bA}$ & $8,50 \mathrm{bA}$ & $8,32 \mathrm{bA}$ & $8,79 \mathrm{bA}$ & $8,43 \mathrm{bA}$ & \\
\hline Picão-preto & & $9,32 \mathrm{aA}$ & $9,01 \mathrm{aA}$ & $8,52 \mathrm{bA}$ & $8,35 \mathrm{bA}$ & $8,32 \mathrm{bA}$ & $8,63 \mathrm{bA}$ & $8,32 \mathrm{bA}$ & \\
\hline Alface & \multirow{4}{*}{ 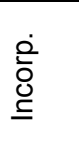 } & $8,76 \mathrm{aB}$ & $8,35 \mathrm{aA}$ & $8,28 \mathrm{aA}$ & $8,23 \mathrm{aA}$ & $8,28 \mathrm{aA}$ & 8,10 aA & $8,12 \mathrm{aA}$ & \\
\hline Tomate & & $8,88 \mathrm{aA}$ & $8,12 \mathrm{bA}$ & $8,25 \mathrm{bB}$ & $8,16 \mathrm{bA}$ & $7,99 \mathrm{bA}$ & $8,25 \mathrm{bA}$ & $7,96 \mathrm{bA}$ & \\
\hline Dente-de-leão & & $8,23 \mathrm{bB}$ & $7,83 \mathrm{bB}$ & $7,86 \mathrm{bA}$ & $7,92 \mathrm{bA}$ & $8,43 \mathrm{bA}$ & $9,72 \mathrm{aA}$ & $9,96 \mathrm{aB}$ & \\
\hline Picão-preto & & $8,55 \mathrm{bB}$ & $8,18 \mathrm{bB}$ & $8,10 \mathrm{bA}$ & $8,14 \mathrm{bA}$ & $8,18 \mathrm{bA}$ & $8,49 \mathrm{bA}$ & $10,24 \mathrm{aB}$ & \\
\hline \multirow{2}{*}{\multicolumn{6}{|c|}{$\begin{array}{l}\text { DMS } \\
\text { Causas da Variação }\end{array}$}} & 1,26 & & & \\
\hline & ção & & & & & $\mathrm{F}_{\text {calc }}$ & & & \\
\hline \multicolumn{6}{|c|}{ Espécie } & $5,28^{\star *}$ & & & \\
\hline \multicolumn{6}{|l|}{ Doses } & $1,78^{\text {ns }}$ & & & \\
\hline \multicolumn{6}{|l|}{ Aplicação } & $3,64^{\mathrm{ns}}$ & & & \\
\hline \multicolumn{6}{|c|}{ Espécie $\mathrm{x}$ doses } & $3,12^{*}$ & & & \\
\hline \multicolumn{6}{|c|}{ Espécie $x$ aplicação } & $1,82^{\mathrm{ns}}$ & & & \\
\hline \multicolumn{6}{|c|}{ Doses x aplicação } & $6,81^{\text {** }}$ & & & \\
\hline \multicolumn{6}{|c|}{ Espécie $\mathrm{x}$ doses $\mathrm{x}$ aplicação } & $3,69^{* *}$ & & & \\
\hline \multicolumn{6}{|l|}{$\mathrm{CV}(\%)$} & 6,29 & & & \\
\hline
\end{tabular}

Tabela 7. Massa verde da parte aérea submetidas a diferentes tipos de aplicação e doses do bioextrato da palha de cana-de-açúcar. TDA: Tipo de aplicação.Médias seguidas pela mesma letra, minúscula na coluna e maiúscula na linha entre cada espécies, não diferem estatisticamente, ao nível de $5 \%$ de probabilidade, pelo teste de Skott-knott. ${ }^{*}{ }^{* *}$ significativo a 5 e $1 \%$ de probabilidade, respectivamente. ns: não significativo.

\begin{tabular}{|c|c|c|c|c|c|c|c|c|c|}
\hline \multirow[t]{2}{*}{ Espécies } & \multirow[t]{2}{*}{ TDA } & \multicolumn{7}{|c|}{ Doses } & \multirow{2}{*}{$\frac{\text { DMS }}{\text { b }}$} \\
\hline & & $0 \%$ & $0,5 \%$ & $1 \%$ & $1,5 \%$ & $2 \%$ & $2,5 \%$ & $3 \%$ & \\
\hline Alface & \multirow{4}{*}{$\grave{2}$} & 26,74 aA & $17,80 \mathrm{aA}$ & 20,33 aA & $13,13 \mathrm{aA}$ & $18,24 \mathrm{aA}$ & $15,42 \mathrm{aA}$ & $15,10 \mathrm{aA}$ & \multirow{8}{*}{9,94} \\
\hline Tomate & & 20,25 aA & 19,38 aA & $16,55 \mathrm{aA}$ & $12,67 \mathrm{aA}$ & $12,55 \mathrm{aA}$ & $19,42 \mathrm{aA}$ & $16,19 \mathrm{aA}$ & \\
\hline Dente-de-leão & & $13,55 \mathrm{aA}$ & $12,96 \mathrm{aA}$ & $11,98 \mathrm{aA}$ & $9,34 \mathrm{aA}$ & 9,94 aA & $10,40 \mathrm{aA}$ & $12,24 \mathrm{aA}$ & \\
\hline Picão-preto & & $21,81 \mathrm{aA}$ & $16,81 \mathrm{aA}$ & $13,33 \mathrm{aA}$ & $9,34 \mathrm{aA}$ & 10,41 aA & $10,94 \mathrm{aA}$ & $14,30 \mathrm{aA}$ & \\
\hline Alface & \multirow{4}{*}{ 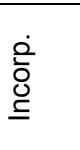 } & $15,30 \mathrm{aB}$ & $12,00 \mathrm{aA}$ & $11,58 \mathrm{aA}$ & $11,33 \mathrm{aA}$ & 13,78 aA & 9,39 aA & $10,88 \mathrm{aA}$ & \\
\hline Tomate & & 17,99 aA & $13,25 \mathrm{aA}$ & $9,73 \mathrm{aA}$ & $10,75 \mathrm{aA}$ & 9,59 aA & $9,73 \mathrm{aA}$ & $8,87 \mathrm{aA}$ & \\
\hline Dente-de-leão & & $14,50 \mathrm{aA}$ & 8,73 aA & $8,28 \mathrm{aA}$ & $9,03 \mathrm{aA}$ & 9,47 aA & $13,41 \mathrm{aA}$ & $12,48 \mathrm{aA}$ & \\
\hline Picão-preto & & $14,27 \mathrm{aA}$ & $9,00 \mathrm{aA}$ & 8,76 aA & $9,51 \mathrm{aA}$ & $10,95 \mathrm{aA}$ & $14,99 \mathrm{aA}$ & $13,04 \mathrm{aA}$ & \\
\hline \multirow{2}{*}{\multicolumn{6}{|c|}{$\begin{array}{l}\text { DMS } \\
\text { Causas da Variação }\end{array}$}} & \multicolumn{3}{|l|}{13,06} & \\
\hline & & & & & & \multicolumn{3}{|l|}{$F_{\text {calc }}$} & \\
\hline \multicolumn{6}{|l|}{ Espécie } & \multicolumn{3}{|l|}{$4,71^{* *}$} & \\
\hline \multicolumn{6}{|l|}{ Doses } & \multicolumn{3}{|l|}{$3,27^{* *}$} & \\
\hline \multicolumn{6}{|l|}{ Aplicação } & \multicolumn{3}{|l|}{$13,63^{* *}$} & \\
\hline \multicolumn{6}{|l|}{ Espécie $\mathrm{x}$ doses } & \multicolumn{3}{|l|}{$0,66^{\mathrm{ns}}$} & \\
\hline \multicolumn{6}{|c|}{ Espécie $\mathrm{x}$ aplicação } & \multicolumn{3}{|l|}{$2,75^{\star}$} & \\
\hline \multicolumn{6}{|c|}{ Doses $x$ aplicação } & \multicolumn{3}{|l|}{$1,39^{\text {ns }}$} & \\
\hline \multicolumn{6}{|c|}{ Espécie $\mathrm{x}$ doses $\mathrm{x}$ aplicação } & \multirow{2}{*}{\multicolumn{3}{|c|}{$\begin{array}{l}1,01^{\mathrm{ns}} \\
48,18\end{array}$}} & \\
\hline \multicolumn{6}{|l|}{$\mathrm{CV}(\%)$} & & & & \\
\hline
\end{tabular}

Comparando os tipos de aplicação entre as dosagens de bioextrato na mesma espécie, conforme Tabela 8, verifica-se que não difere estatisticamente entre a aplicação pulverizada e incorporada para as espécies de alface, tomate e dente-de-leão. Já para a espécie de picão-preto, observa-se diferença significativa, quando a palha foi pulverizada, maior valor foi na dose de $1 \%$ para a espécie de picão-preto.

Examinando o volume da raiz das espécies submetidas a diferentes tipos de aplicação de palha da cana-de- 
Revista de la Facultad de Agronomía, La Plata (2020) Vol 119 (1): 1-11

açúcar, de acordo com a Tabela 9, foi observado que as doses não diferiram estatisticamente quando a palha foi pulverizada nas espécies de alface e tomate. No entanto, para a espécie de dente-de-leão e picão-preto verifica-se diferença estatística, com maiores valores na da raiz da planta.
Já dose de $0,5 \%$, e 0 e $0,5 \%$ respectivamente, e nas demais doses observa-se a redução nos valores de volume quando a palha foi incorpora as doses não deferiram estatisticamente entre si, em todas as espécies em estudo.

Tabela 8. Massa verde da raiz a diferentes tipos de aplicações e doses do bioextrato da palha de cana-de-açúcar. TDA: Tipo de aplicação. Médias seguidas pela mesma letra, minúscula na coluna e maiúscula na linha entre cada espécies, não diferem estatisticamente, ao nível de $5 \%$ de probabilidade, pelo teste de Skott-knott. * e ${ }^{* *}$ significativo a 5 e $1 \%$ de probabilidade, respectivamente. ns: não significativo.

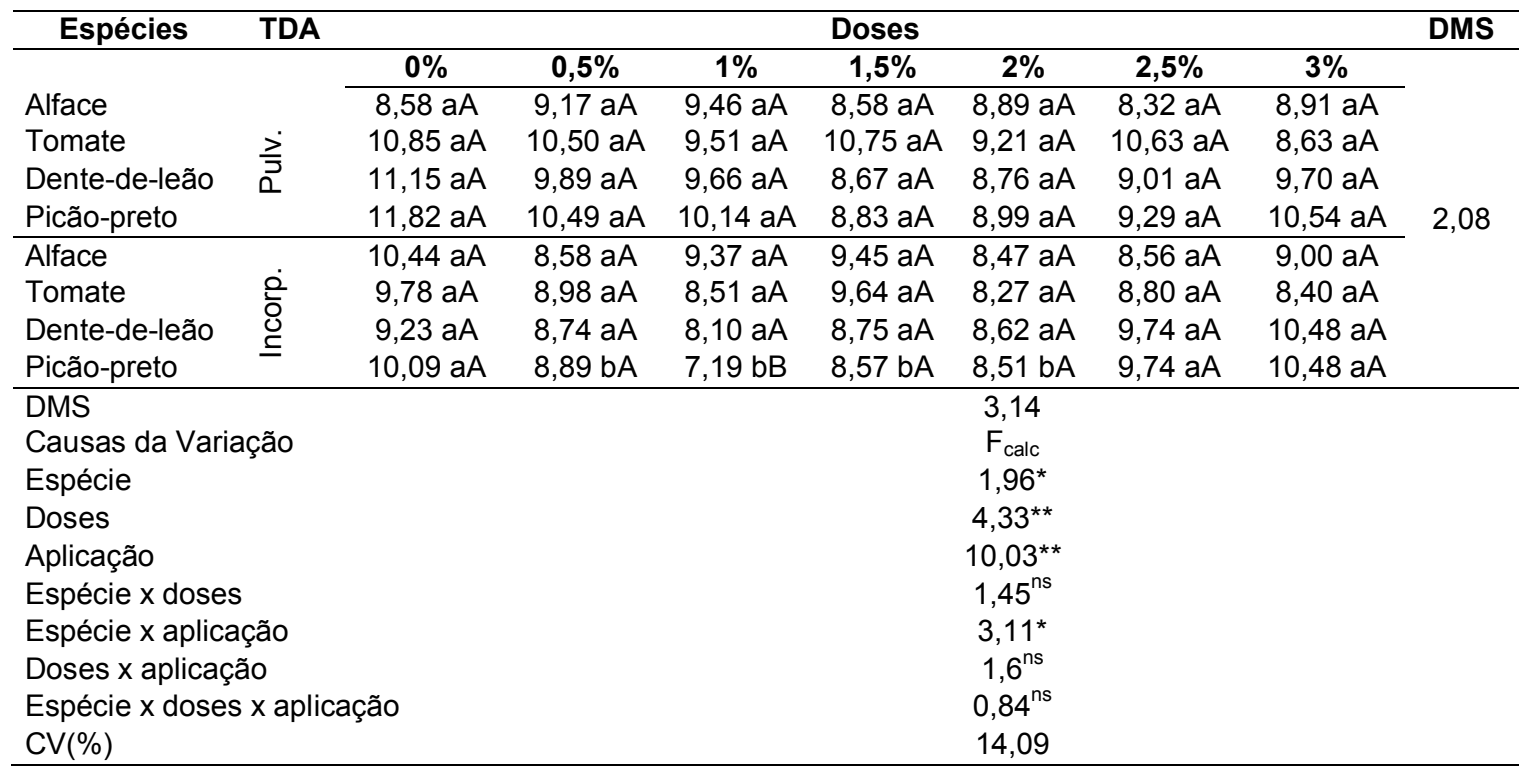

Tabela 9. Volume da raiz a diferentes tipos de aplicações e doses do bioextrato da palha de cana-de-açúcar. TDA: Tipo de aplicação. Médias seguidas pela mesma letra, minúscula na coluna e maiúscula na linha entre cada espécies, não diferem estatisticamente, ao nível de $5 \%$ de probabilidade, pelo teste de Skott-knott. ${ }^{*}{ }^{* *}$ significativo a 5 e $1 \%$ de probabilidade, respectivamente. ns: não significativo.

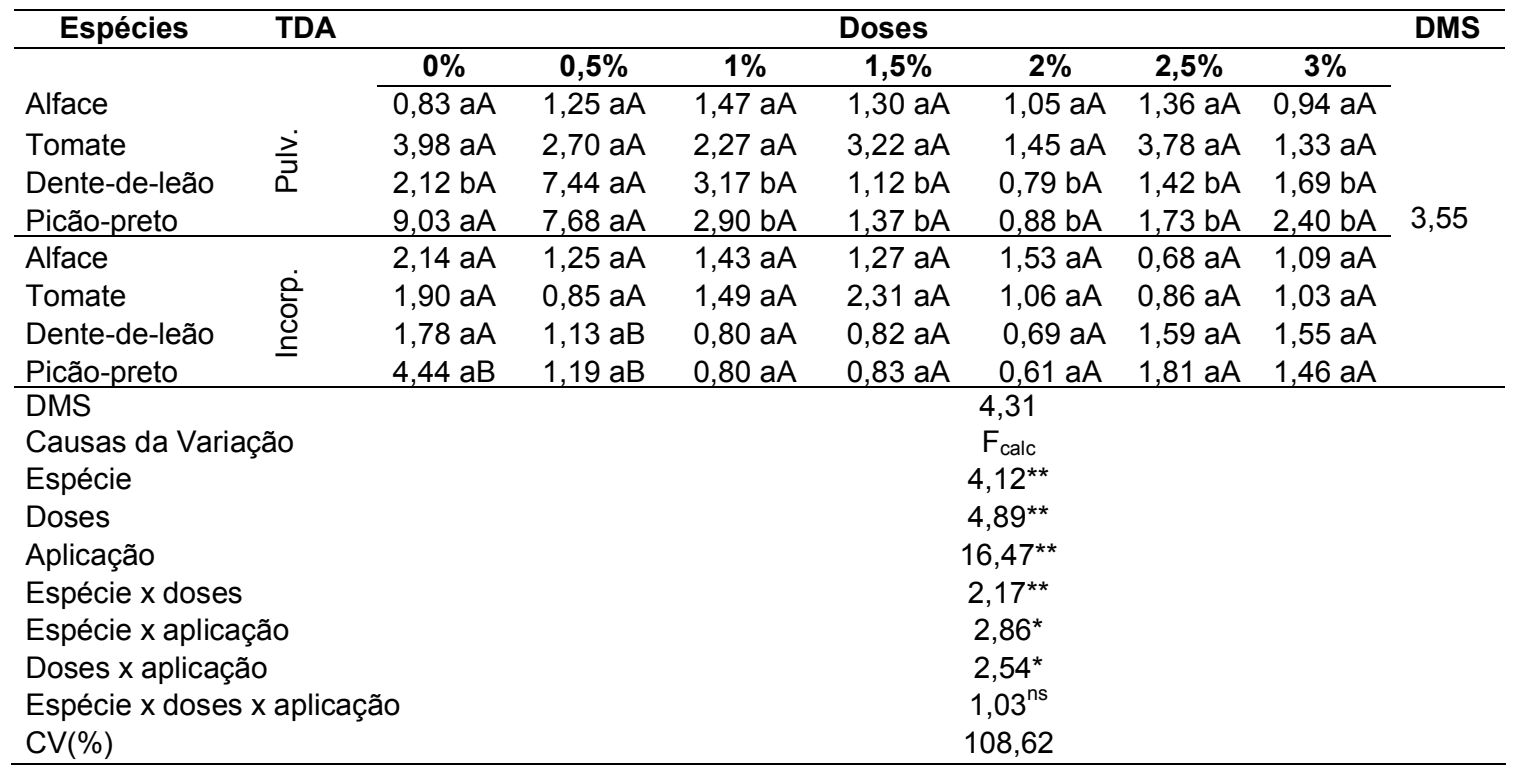


Comparando os tipos de aplicação entre as dosagens de bioextrato na mesma espécie (Tabela IX), verifica-se que não difere estatisticamente entre a aplicação pulverizada e incorporada para as espécies de alface e tomate. No entanto, para a espécie de dente-de-leão e picão-preto observa-se diferença significativa, sendo que, a palha quando pulverizada obteve maiores valores na testemunha $(0 \%)$ e nas doses de 0 e $0,5 \%$, respectivamente. Para as demais doses verifica-se menores valores no volume radicular.

Com os resultados deste estudo, verifica-se a necessidade da continuação deste trabalho, onde poderá ser isolado $\mathrm{e}$ identificado o composto fitoquímico inibitório da palha e do bioextrato da palha de cana-de-açúcar para utilização de controle natural de plantas daninhas (dente-de-leão e picão-preto), também no bioextrato da palha da cana-de-açúcar poderá ser isolado e identificado um composto químico e utilizado como estimulador no desenvolvimento de plantas cultivadas (alface e tomate).

\section{CONCLUSÃO}

As doses do bioextrato de palha da cana-de-açúcar estimulou o comprimento da parte aérea das plantas daninhas (dente-de-leão e picão-preto) e inibiu o seu percentual de germinação.

As doses de palha da cana-de-açúcar podem inibir ou estimular o desenvolvimento conforme a testemunha. As espécies foram inibidas quando pulverizada a palha da cana-de-açúcar em todas as variáveis analisadas.

Agradecimento

À FAPEMIG pela concessão da bolsa de estudo.

\section{REFERÊNCIAS}

Almeida, F.S. 1992. Herbicidas residuais em diferentes sistemas de preparo do solo. Pesquisa Agropecuária Brasileira 27(4): 596-601.

Bianchi, M.A., N.G. Fleck, D. Agostinetto \& M.A. Rizzardi. 2011. Interferência de Raphanus sativus na produtividade de cultivares de soja. Planta Daninha, 29:783-792.

BRASIL. Ministério da Agricultura e Reforma Agrária. 2009. Regras para análise de sementes. Brasília: SNDA. 395 p.

Chou, C.H. 1992. Allelopathyc in relation to agriculture productivity in Taiwan: problems and prospects. In: Allelopathy: basic and applied aspects., J.H Rizvi; Rizvi, V. Chapman \& Hall, London pp 179-203.

Companhia Nacional de Abastecimento - CONAB. 2014. Acompanhamento de safra brasileira: cana-deaçúcar, safra 2014/2015, terceiro levantamento. Brasília: Conab, 2014. 27 pp.

Companhia Nacional de Abastecimento - CONAB. 2016. Acompanhamento de safra brasileira: cana-deaçúcar, safra 2016/2017, terceiro levantamento. Dez. Brasília: CONAB, 2016. 78 pp.

Empresa Brasileira de Pesquisa Agropecuária (EMBRAPA). 2018. Sistema brasileiro de classificação de solos. Brasilia: Embrapa Solos. 5. ed. 356 pp.
Ferreira, A. G. \& F. Borguetti. 2004. Germinação do básico ao aplicado. Porto Alegre, RS: Artmed.

Ferreira, D.F. 2011. Sistema para análise de variância para dados balanceados (SISVAR versão 5.6). Lavras, Universidade Federal de Lavras. Software Registrado TM.

Gazziero, D.L.P. \& I.F Souza. 1993. Manejo integrado de plantas daninhas. In: Cultura da soja nos cerrados. Arantes, N. E.; Souza, P. I. M. Potafós. Piracicaba, SP. 535 pp

Gomes Jr., F.G. \& P.J. Christoffoleti. 2008. Biologia e manejo de plantas daninhas em áreas de plantio direto. Planta Daninha 26(4): 789-798.

Gomes, D.S., N. C. Bevilaqua, F. B. Silva \& P. A. Monquero. 2014. Supressão de plantas espontâneas pelo uso de cobertura vegetal de crotalária e sorgo. Revista Brasileira de Agroecologia, 9(2), 206-213.

Guidotti, B.B., B.R. Gomes, R.C.S. Soares, A.R. Soares \& O. Ferrarese Filho. 2013. The effects of dopamine on root growth and enzyme activity in soybean seedlings. Plant Signal Behav 8(1): 1-7.

Maguire, J.D. 1962. Speed of germination aid in selection and evaluation for seedling emergence and vigor. Crop Science 2(1): 176-177.

Medina-Melendez, J.A. 1990. Efeito da cobertura do solo no controle de plantas daninhas na cultura do pepino (Cucumis sativus L.). Piracicaba.. (Mestrado) Escola Superior de Agricultura "Luiz de Queiroz", na Universidade de São Paulo. 104 pp.

Microcal Origin. 1999. Origin Version 6.1. Microcal Software, Inc., Northampton. .

Monquero, P.A., L.R. Amaral, E.R. Inácio, J.P. Brunhara, D.P. Binha, P.V. Silva \& A.C. Silva. 2009. Efeito de adubos verdes na supressão de espécies de plantas daninhas. Planta Daninha, 27: 85-95.

Oliveira Jr., R.S., J. Constantin \& M.H. Inoue. 2011. Biologia e manejo de plantas daninhas. Curitiba, PR: Omnipax, $48 \mathrm{pp}$

Ribeiro, J.P.N. \& I.M.S. Lima. 2012. Allelopathic effects of orange (Citrus sinensis L.) peel essential oil. Acta Bot. Bras. 26(1) Feira de Santana Jan./Mar.

Rizzardi, M.A. \& L.F. Silva. 2006. Influência das coberturas vegetais de aveia-preta e nabo forrageiro na época de controle de plantas daninhas em milho. Planta Daninha, 24(4): 669-675.

Rossi, C.V.S. 2007. Controle de plantas daninhas pelos herbicidas Metribuzin e Isoxaflutole em soqueira de cana-de-açúcar, na ausênica e presença de palha. Tese (Doutorado em Agronomia - Area de concentração em Agricultura) Faculdade de Ciências Agronômicas. Universidade Estadual Paulista. Botucatu.

Santos, C.C. 2002. Efeitos dos resíduos do milho sobre o desenvolvimento de cafeeiros (Coffea arabica L.). 62 p. Dissertação (Mestrado em Fitotecnia) - Universidade Federal de Lavras, Lavras, MG.

Seifert, G. \& E. Voll. 2000. Cobertura de aveia e calagem sobre amendoim-bravo em semeadura direta de soja. Planta Daninha, Viçosa 18: 309-322.

Severino, F.J. \& P.J. Christoffoleti. 2001. Efeitos de quantidades de fitomassa de adubos verdes na supressão de plantas daninhas. Planta Daninha, 19: 223-228.

Soares, M.B.B., E.L. Finoto, D. Bolonhezi, W.C. Carrega, J.A.A. Albuquerque \& M.Z. Pirotta. 2011. 
Fitossociologia de plantas daninhas sob diferentes sistemas de manejo de solo em áreas de reforma de cana-crua. Revista Agro@mbiente 5(3): 173-181.

Trivelin, P.C.O., J.C.S. Rodriguês, R.L. Victoria \& K. Reichardt. 1996. Utilização por soqueira de cana-deaçúcar de início de safra do nitrogênio da aquamônia ${ }^{-15}$ $\mathrm{N}$ e ureia $^{-15} \mathrm{~N}$ aplicado ao solo em complemento à vinhaça. Pesquisa Agropecuária Brasileira 31: 89-99.

Velini, E.D. \& E. Negrisoli. 2000. Controle de plantas daninhas em cana-crua. In: Congresso Brasileiro Da Ciência Das Plantas Daninhas, 22, 2000, Foz do Iguaçu. Anais... Foz do Iguaçu: SBCPD.
Venegas, V.H.A. \& G.A.M. Alvarez. 2003. Apresentação de equações de regressão e suas interpretações. Sociedade Brasileira de Ciência do Solo, Viçosa-MG 28(3): 28-32.

Wichers, H.J, J.F. Visser, H.J. Huizing \& N. Pras. 1993. Occurrence of I-dopa and dopamine in plants and cell-cultures of Mucuna pruriens and effects of 2,4-d and $\mathrm{NaCl}$ on these compounds. Plant Cell, Tissue and Organ Culture 33: 259-264.

Zaprometov M.N. 1992. On the functional role of phenolic compounds in plants. Soviet Journal of Plant Physiology. p. 802-809. 